\title{
Effects of platelet activating factor on airway calibre, airway responsiveness, and circulating cells in asthmatic subjects
}

\author{
K F CHUNG, P J BARNES
}

From the Department of Thoracic Medicine, National Heart and Lung Institute, Brompton Hospital, London

ABSTRACT The effects of inhaled platelet activating factor were compared with those of inhaledmethacholine (control) on airway calibre, airway responsiveness to methacholine and isoprenaline, $\infty$ and circulating cells in eight subjects with mild, stable asthma. Platelet activating factor was given in six doses at 15 minute intervals and airway response measured as change in partial expiratory flow at ${ }^{-}$ $30 \%$ of vital capacity $\left(\dot{\mathrm{V}} \mathrm{p}_{30}\right)$. Platelet activating factor caused a fall in $\dot{\mathrm{V}} \mathrm{p}_{30}$, the mean $(\mathrm{SEM}) \mathbb{O}$ maximum percentage fall being $28.9(4.2)$ five minutes after the first dose $(12 \mu \mathrm{g})$ and $50.9(8.0)$ after the second dose $(24 \mu \mathrm{g})$. Tachyphylaxis occurred, however, with the four subsequent doses of inhaled platelet activating factor. There was transient neutropenia after the first dose, from a mean of $3.6(0 \cdot 2) \vec{\bullet}$ $\times 10^{9}$ to $2.2(0.5) \times 10^{9}$ neutrophils/l; this response also showed tachyphylaxis with subsequent $0_{0}^{\infty}$ doses. The mean $\mathrm{PC}_{40}$ (the concentration of methacholine needed to cause a $40 \%$ fall in $\mathrm{Vp}_{30}$ ) was unchanged one, three, and seven days after administration of platelet activating factor. There was no significant correlation between baseline $\mathrm{PC}_{40}$ methacholine and the maximal fall in $\dot{\mathrm{V}} \mathrm{p}_{30}$ after either the first $(12 \mu \mathrm{g})$ or the second dose $(24 \mu \mathrm{g})$ of platelet activating factor. The control challenge with methacholine produced a degree of bronchoconstriction similar to that of platelet activating factor ${ }_{\Omega}^{\mathbb{Q}}$ but was not associated with any significant change in bronchial responsiveness or in circulating cells. $\overrightarrow{\vec{O}}$ The bronchodilator response to inhaled isoprenaline measured three days after inhalation of platelet 3 activating factor and of methacholine was similar after the two challenges. Thus asthmatic subjects? who are hyperresponsive to methacholine show a similar bronchoconstrictor response to platelet: activating factor, as has been observed in normal subjects; overall this did not cause airway hyperresponsiveness to methacholine.

\section{Introduction}

Platelet activating factor is a potent mediator of inflammation that mimics several of the features that characterise asthmatic airways. ${ }^{12}$ It is a potent inducer of microvascular leakage in guinea pig airways, being at least 10000 times more potent than histamine in this regard. ${ }^{3}$ In normal, non-asthmatic subjects, inhalation of platelet activating factor causes an acute, transient bronchoconstriction and, perhaps more important, an increase in airway responsiveness to methacholine, ${ }^{45}$ an effect that may last for many weeks. ${ }^{4}$ Such changes have been produced experimentally in the guinea pig, ${ }^{6}$ $\operatorname{dog}^{7}$ and sheep. ${ }^{8}$ Another interesting property of

Address for reprint requests: Dr K F Chung, National Heart and Lung Institute, Brompton Hospital, London SW3 6HP.

Accepted 15 November 1988 platelet activating factor is its chemotactic action on $\frac{3}{3}$ human eosinophils, ${ }^{910}$ cells that characteristically infiltrate the airways of patients with acute, severe $\frac{3}{3}$ asthma ${ }^{11}$ and may have a crucial role in the pathogenesis of bronchial hyperresponsiveness. ${ }^{12}$

In the present study we examined the effects of $\rightarrow$ inhaled platelet activating factor on airway calibre and airway responsiveness in eight subjects with mild N asthma, using a protocol identical to that previously used in normal subjects. ${ }^{4}$ If platelet activating factor is released endogenously in asthmatic airways, $\omega$ asthmatic individuals might not be as responsive to 2 platelet activating factor as normal people, in view of the known development of tachyphylaxis in the response to it both in man and in animals. ${ }^{413}$ As in ${ }^{+}$ animals pretreatment with platelet activating factor ${ }^{-}$ reduces the bronchodilator effect of isoprenaline ${ }^{14}$ and $\stackrel{\mathbb{\mathbb { P }}}{\mathrm{O}}$ as there is evidence that it causes down regulation of $\frac{\mathbb{P}}{\mathbb{P}}$ beta adrenoceptors in human lung in vitro, ${ }^{15}$ we 
Characteristics of the asthmatic subjects

\begin{tabular}{|c|c|c|c|c|c|c|c|}
\hline \multirow{2}{*}{$\begin{array}{l}\text { Subject } \\
\text { No }\end{array}$} & \multirow[b]{2}{*}{ Sex } & \multirow[b]{2}{*}{ Age (y) } & \multicolumn{2}{|c|}{$F E V_{1}(B P T S)$} & \multirow{2}{*}{$\begin{array}{l}P C_{40} \dagger(\mathrm{mg} / \mathrm{ml} \\
\text { methacholine) }\end{array}$} & \multirow{2}{*}{$\begin{array}{l}\text { Smoking } \\
\text { (cigarettes/day) }\end{array}$} & \multirow{2}{*}{$\begin{array}{l}\text { Medication } \\
\text { (inhaled salbutamol) }\end{array}$} \\
\hline & & & Actual (l) & Predicted $(\%)$ & & & \\
\hline $\begin{array}{l}1 \\
2 \\
3 \\
4 \\
5 \\
6 \\
7 \\
8\end{array}$ & $\begin{array}{l}\mathbf{M} \\
\mathbf{M} \\
\mathbf{F} \\
\mathbf{M} \\
\mathbf{M} \\
\mathbf{F} \\
\mathbf{M} \\
\mathbf{F}\end{array}$ & $\begin{array}{l}31 \\
24 \\
27 \\
32 \\
23 \\
33 \\
24 \\
29\end{array}$ & $\begin{array}{l}3 \cdot 85 \\
2 \cdot 81 \\
3 \cdot 10 \\
3 \cdot 52 \\
3 \cdot 75 \\
3 \cdot 0 \\
4 \cdot 3 \\
2 \cdot 55\end{array}$ & $\begin{array}{l}3 \cdot 92(98) \\
3 \cdot 28(86) \\
3 \cdot 36(92) \\
3 \cdot 89(91) \\
4 \cdot 54(83) \\
3 \cdot 10(97) \\
4 \cdot 34(100) \\
3 \cdot 0(85)\end{array}$ & $\begin{array}{l}0.56 \\
0.35 \\
1.74 \\
0.26 \\
0.49 \\
6.4 \\
0.50 \\
0.30\end{array}$ & $\begin{array}{r}0 \\
0 \\
10 \\
20 \\
0 \\
0 \\
0 \\
0\end{array}$ & $\begin{array}{l}\text { Occasional† } \\
\text { Occasional } \\
\text { Regular§ } \\
\text { Regular } \\
\text { Occasional } \\
\text { Nil } \\
\text { Nil } \\
\text { Regular }\end{array}$ \\
\hline
\end{tabular}

*According to Quanjer (Clin Respir Physiol 1983;suppl 5:1-95).

+Provocative concentration of methacholine needed to cause a $\mathbf{4 0} \%$ fall in baseline $\mathrm{Vp}_{\mathbf{3 0}}$. †About $400-800 \mu \mathrm{g} /$ week.

\$At least $400 \mu \mathrm{g} / \mathrm{day}$.

investigated whether it altered the bronchodilator response to isoprenaline in these asthmatic subjects. Finally, because platelet activating factor causes a fall in circulating cells, such as platelets and leucocytes, in animals ${ }^{1617}$ and normal subjects, ${ }^{18}$ we measured platelet and white cell counts in peripheral blood.

\section{Methods}

\section{SUBJECTS}

Eight subjects with mild asthma (table) were recruited for the study, which was approved by the National Heart and Chest Hospital's ethics committee. All subjects gave informed consent. All were atopic as assessed by skin weal and flare responses to prick tests performed with a battery of common allergens. Five subjects were taking intermittent inhaled beta agonists but none of the subjects was receiving oral bronchodilators or corticosteroids. All subjects had to have been free of upper respiratory tract infections or exacerbations of asthma symptoms for at least four weeks at the start of each study period. They had to avoid beverages containing caffeine for two hours before challenge on each day and inhaled beta agonists for at least eight hours.

\section{STUDY DESIGN}

Each subject was studied during two periods separated by at least four weeks so that the effect of platelet activating factor and a control inhalation challenge (methacholine) could be compared. The order of the two periods was randomised and subjects were not told whether they were receiving platelet activating factor or methacholine. During each period the subject attended the laboratory on seven occasions over eight or nine days. Airway responsiveness to inhaled methacholine and inhaled isoprenaline was measured initially and this was followed one or two days later by an inhalation challenge of either platelet activating factor or methacholine control aerosol. Responsiveness to methacholine was measured one, three and seven days after the platelet activating factor and control methacholine inhalation. This protocol was chosen on the basis of a previous study that had shown that the maximum increase in airway responsiveness occurred three days after platelet activating factor inhalation in normal subjects. ${ }^{4}$ Airway responsiveness to isoprenaline was also measured three days after platelet activating factor and control methacholine inhalation. All isoprenaline and methacholine challenges were performed at similar times of day for each subject, the isoprenaline challenge being performed at least four hours after methacholine challenge on the same day. An intravenous cannula (21G, Venflon, Viggo AB, Sweden) was inserted 15 minutes before platelet activating factor and control methacholine inhalation, for venous blood sampling.

\section{PLATELET ACTIVATING FACTOR AND}

\section{METHACHOLINE CONTROL INHALATION} CHALLENGE

Platelet activating factor (Novabiochem AG, Switzerland) was stored in $100 \%$ ethanol at $-20^{\circ} \mathrm{C}$ at a concentration of $10 \mathrm{mg} / \mathrm{ml}$. On the study day a $2 \mathrm{mg} /$ $\mathrm{ml}$ solution was prepared in $0.9 \%$ saline containing a final concentration of $0.03 \%$ heat treated human serum albumin. Platelet activating factor aerosol was delivered from a nebuliser attached to a dosimeter (MEFAR, Brescia, Italy) driven by compressed air at a pressure of $22 \mathrm{lb} / \mathrm{in}^{2}(152 \mathrm{kPa})$. Each nebulisation lasted for 1.0 second and was timed to occur as the subject inhaled for three seconds from functional residual capacity to total lung capacity, after which he held his breath for seven seconds before breathing out normally. The output of the nebuliser was $6 \mu \mathrm{l}$ a breath. We administered one puff of platelet activating factor $(12 \mu \mathrm{g})$ followed by two puffs of platelet activating factor $(24 \mu \mathrm{g})$ at 15 minute intervals on five occasions (total dose $132 \mu \mathrm{g}$ ).

On the control day one breath of methacholine dissolved in $0.9 \%$ saline and $0.03 \%$ heat treated human serum albumin was administered in a dose determined to cause a degree of bronchoconstriction 
similar to that induced by the inhaled platelet activating factor. Fifteen minutes later a doubling dose of methacholine was given, followed by four consecutive doses of two breaths of the diluent only. The dose of methacholine administered to each subject was determined from the subject's response to methacholine as previously measured.

The response to platelet activating factor and methacholine was measured from volume standardised partial expiratory flow-volume curves. ${ }^{19}$ Use of a sensitive measurement of bronchoconstriction reduced the necessity for administering large doses of platelet activating factor or methacholine. Flowvolume curves were obtained with a rolling spirometer (Vitalograph,) and analysed with a Hewlett-Packard microcomputer (Collingwood Measurement, Leicester). The flow-volume curves were stored and displayed later. Subjects initially performed a full expiration to vital capacity, and measurements of flow were then made at $30 \%$ of vital capacity above residual volume, measured from total lung capacity $\left(\mathrm{V} \mathrm{p}_{30}\right)$. The subject performed a flow-volume manoeuvre by means of a forced expiration from just above tidal inspiration to residual volume, followed by inhalation to total lung capacity before breathing out normally. All subjects were trained in these breathing manoeuvres before entering the study. Measurements of $\dot{V} p_{30}$ were made one, three, five, 10 , and 15 minutes after each inhalation of platelet activating factor. Change in $\dot{\mathrm{V}} \mathrm{p}_{30}$ was expressed as the percentage change from the mean of three control $\dot{\mathrm{V}} \mathrm{p}_{60}$ measurements.

\section{MEASUREMENTS OF AIR WAY RESPONSIVENESS TO METHACHOLINE}

Methacholine chloride (Sigma,) was dissolved in 0.9\% sodium chloride and stored at $4^{\circ} \mathrm{C}$. Before use the solution was allowed to warm to room temperature. Increasing doubling concentrations from 0.03 to 16 $\mathrm{mg} / \mathrm{ml}$ were used, after determination of an appropriate initial concentration for each subject at a preliminary visit. After three baseline values of $\dot{V} p_{30}$ had been obtained the subject inhaled four breaths of $0.9 \%$ sodium chloride from the dosimeter. $\dot{V} p_{30}$ was measured after 90 and 150 seconds and the mean $\dot{V} p_{30}$ obtained. The subject then inhaled the concentration of methacholine determined at the preliminary visit, followed by a succession of doubling concentrations (four breaths) every three minutes until $\dot{V} \mathrm{p}_{30}$ had fallen by about half. The provocative concentration of methacholine needed to cause a $40 \%$ fall in $\mathrm{V}_{30}\left(\mathrm{PC}_{40}\right)$ was then computed.

ISOPRENALINE CHALLENGE

Isoprenaline aerosols $(1 \%$, Aleudrine, Lewis Laboratories Ltd, Leeds) were administered as
$0.025 \%, 0.2 \%$, and $1 \%$ solutions every eight minutes and delivered from the same nebuliser (attached to as dosimeter) that was used for the methacholine challen-O ges. Increasing doses of isoprenaline $(3,6,24,48,120$,을 and $240 \mu \mathrm{g}$ ) were inhaled; $\mathrm{Vp}_{30}$ was measured five, six, and seven minutes after each inhalation and the mean was calculated. Change in $\dot{\mathrm{V}} \mathrm{p}_{30}$ was expressed as percentage change from the control $\dot{\mathrm{V}} \mathrm{p}_{30} \overrightarrow{\mathrm{O}}$ measurement.

MEASUREMENT OF CIRCULATING BLOOD CELLS Venous blood $(2 \mathrm{ml})$ was taken before and five and $15 \overrightarrow{\vec{x}_{x}}$ minutes after the first three inhalations of platelet activating factor or methacholine placebo and placed in tubes containing disodium edetate. Total whiteblood cell and platelet counts were made with aळ Coulter Counter 880 (Coulter Electronics, Hialeah,, Florida). Blood smears were made from each sampleand stained with May-Grünwald-Giemsa stain. T Differential cell counts were performed on 100 cells: from each smear by an independent observer. Then numbers of eosinophils, neutrophils, and lymphocytes per $\mathrm{mm}^{3}$ of blood were estimated by multiplying the $\overrightarrow{0}$ percentage of each cell type by the total white cellọ count and converted to counts per litre.

DATA ANALYSIS

All data are reported as means and standard errors Changes in $\dot{\mathrm{V}}_{30}$ and circulating blood cell counts afterषि platelet activating factor or control methacholine challenge were compared with baseline values obtained before inhalation of platelet activating factor by paired Students' $t$ tests. $\mathrm{PC}_{40}$ values were logarith mically transformed before analysis. Linear regression of $\mathrm{PC}_{40}$ methacholine on change in $\dot{\mathrm{V}}_{30}$ after inhala $-\overrightarrow{\overrightarrow{0}}$ tion of platelet activating factor was determined by then least squares method. To determine whether platelet $x$ activating factor or control methacholine altered airway responsiveness, we used an analysis of variancen for repeated measures. ${ }^{20}$ Period and carryover effectş in the crossover design were assessed. Mean $\dot{V} p_{30}$ values after each dose of isoprenaline before and three days after methacholine control or platelet activatingo factor inhalation were compared by paired Students' tests. $P$ values of less than 0.05 were consideredo statistically significant.

\section{Results}

All subjects noticed facial flushing and coughing after? inhaling the first dose of platelet activating factor $\left(12_{0}\right.$ $\mu \mathrm{g})$ and to a lesser extent after the second (higher) dose $(24 \mu \mathrm{g})$. No further symptoms accompanied the later品 doses. The bronchoconstrictor response to metha choline was not accompanied by flushing or coughing. 
TIME (min)

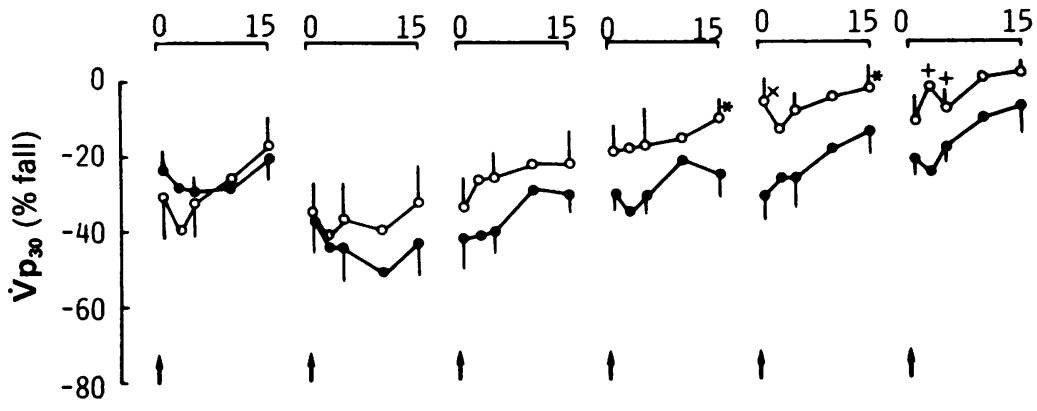

Fig 1 Effect of inhaled platelet activating factor (PAF, ) and methacholine (control, $\bigcirc$ ) on mean (SEM) values of partial expiratory flow at $30 \%$ vital capacity $\left(\dot{V} p_{30}\right)$ in eight asthmatic subjects. ${ }^{*} p<0.05$, $+p<0.02$, and $\times p<0.001$ indicate significant differences between methacholine and platelet activating factor.
CHANGE IN Vं p $_{30}$ WITH PLATELET ACTIVATING FACTOR AND METHACHOLINE CONTROL INHALATION

The first inhalation of platelet activating factor $(12 \mu \mathrm{g})$ induced a fall in $\dot{V} p_{30}$ that was maximal $(28.9 \%$ $(4.2 \%))$ at five minutes ( $p<0.001$; fig 1$)$. A larger fall in $\dot{V} p_{30}(44.5 \%(8.5 \%))$ occurred five minutes after the second dose $(24 \mu \mathrm{g})(\mathrm{p}<0.001)$. Further inhalations of $24 \mu \mathrm{g}$ caused no further fall in $\mathrm{V}_{30}$, and there was some recovery with the sixth inhalation. None of the subjects complained of further wheezing or coughing over the subsequent 24 hours. On the control day inhalation of the first two doses of methacholine caused a fall in $\dot{V} p_{30}$ similar to that induced by platelet activating factor, but recovery from methacholine induced bronchoconstriction was more rapid after methacholine than after the third to sixth dose of platelet activating factor (fig 1). There was no sig- nificant correlation between $\mathrm{PC}_{40}$ methacholine and the percentage fall in $\dot{V} p_{30}$ after either the first (Spearman rank correlation: $r_{s}=0.71 ; p>0.05$ ) or the second inhalation of platelet activating factor $\left(r_{s}=\right.$ $0 \cdot 40$; NS, fig 2).

\section{EFFECT ON CIRCULATING WHITE CELLS}

There were no significant changes in circulating white blood cells, neutrophils, eosinophils, lymphocytes, or platelets after the methacholine control challenge. After the first dose of platelet activating factor inhalation the mean (SEM) total white cell count fell from $6.49(0.41)$ to $4.69(0.72) \times 10^{9} / 1$ at five minutes $(\mathrm{p}<$ $0.005)$, with recovery by 15 minutes. After the second dose of platelet activating factor, there was a further but smaller fall to $5.39(0.71) \times 10^{9} / 1(\mathrm{p}<0.02)$, with some recovery by 15 minutes (fig 3 ). No further significant alterations in total white cell count were

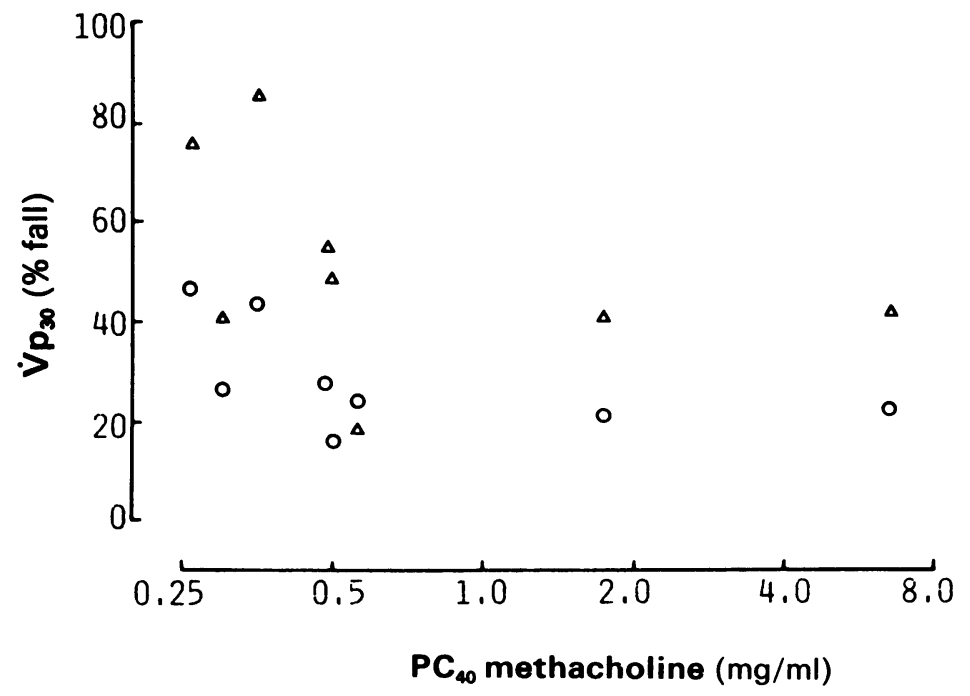

Fig 2 Relation between the provocative concentration of methacholine causing a $40 \%$ fall in $V p_{30}$ $\left(P C_{40}\right)$ and the airway response (\% fall in $\left.V p_{30}\right)$ to the first $(\mathrm{O})$ and second $(\triangle)$ doses (12 and $24 \mu \mathrm{g}$ ) of platelet activating factor (PAF) in the eight asthmatic subjects. There was no significant linear correlation for either set of data. 


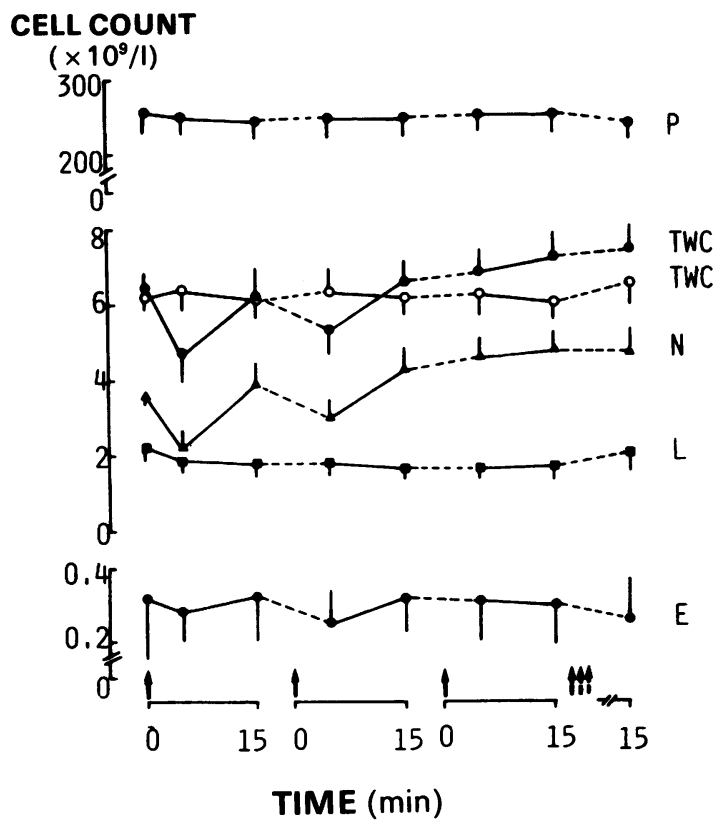

Fig 3 Effect of the first three inhalations of platelet activating factor (PAF, ) on mean (SEM) counts of circulating platelets $(P)$, total white cells $(T W C)$, neutrophils $(N)$, lymphocytes $(L)$, and eosinophils $(E)$ after the first three inhalations (as indicated by the arrows). There was a transient fall in the neutrophil count after the first inhalation of platelet activating factor $(p<0.02)$ but the response showed rapid tachyphylaxis. The effect of methacholine $(O)$ on total white cell count is also shown.

seen after the third inhalation of platelet activating factor. The fall in total white cell count was associated with a fall in the circulating neutrophil count from 3.63 $(0.2)$ to $2.24(0.51) \times 10^{9} / 1$ within five minutes of the first inhalation $(\mathrm{p}<0.02)$. A non-significant rebound neutrophilia $\left(4.72(0.67) \times 10^{9} / 1\right)$ occurred at the end of the platelet activating factor challenge. There were no significant changes in eosinophil, lymphocyte, or platelet counts.

BRONCHIAL RESPONSIVENESS TO METHACHOLINE AND ISOPRENALINE

No significant period and carryover effects on $\mathrm{PC}_{40} \vec{\circ}$ were observed. There were no significant changes in $\vec{\omega}$ geometric mean $\mathrm{PC}_{40}$ methacholine values after $\mathrm{S}$ platelet activating factor $(\mathrm{F}$ value 1.60$)$ or metha- $\vec{x}$ choline control (F value 1.70) exposure (fig 4). There were no significant differences between mean baseline $\dot{\mathrm{V}} \mathrm{p}_{30}$ on the days when bronchial responsiveness to methacholine was measured.

The changes in $\mathrm{V}_{30}$ that occurred after all doses ofo isoprenaline were not significantly altered on day $3 \rightarrow$ after control methacholine inhalation or on day 3 after T platelet activating factor inhalation (fig 5). Meano baseline $\dot{V} p_{30}$ before isoprenaline exposure was not significantly different between day 0 and day 3 for either the platelet activating factor or the control $\overrightarrow{0}$ periods.

\section{Discussion}

We have shown that inhalation of platelet activating factor causes acute bronchoconstriction in subjects $\frac{}{\varnothing}$ with mild asthma; overall, there was no significant $\varrho$ change in bronchial responsiveness to methacholine $\overline{\bar{O}}$ and isoprenaline after platelet activating factor. As in $\exists$ normal subjects, ${ }^{1821}$ there was a transient but pronounced neutropenia immediately after inhalation of platelet activating factor, but this was not accompanied by any change in circulating platelet numbers.

The current data from asthmatic subjects provide an $\times$

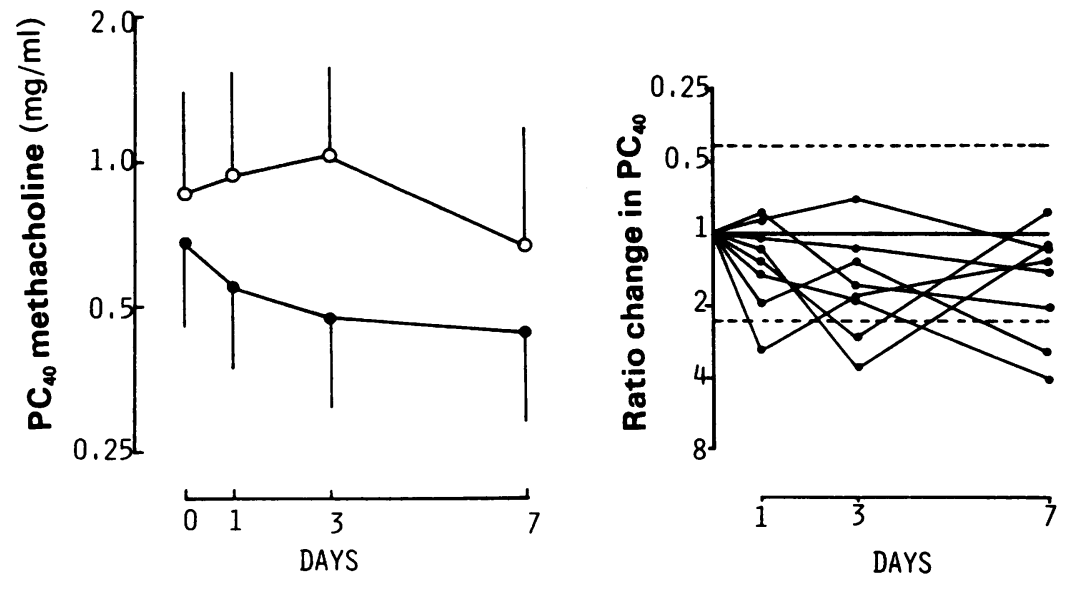

Fig 4 Left hand panel: Effect of methacholine (control, $\bigcirc$ ) and platelet activating factor (PAF, ) on bronchial responsiveness to methacholine as measured by the mean (SEM) concentration of methacholine needed to cause a $40 \%$ fall in baseline $V p_{30}$ $\left(P C_{40}\right)$. The reduction in $P C_{40}$ on days 1,3 , and 7 after exposure to platelet activating factor was not significant. Right hand panel: Individual ratio changes in $P C_{40}$ after platelet activating factor. The dotted horizontal lines represent the $95 \%$ confidence intervals for the five "control" measurements. 

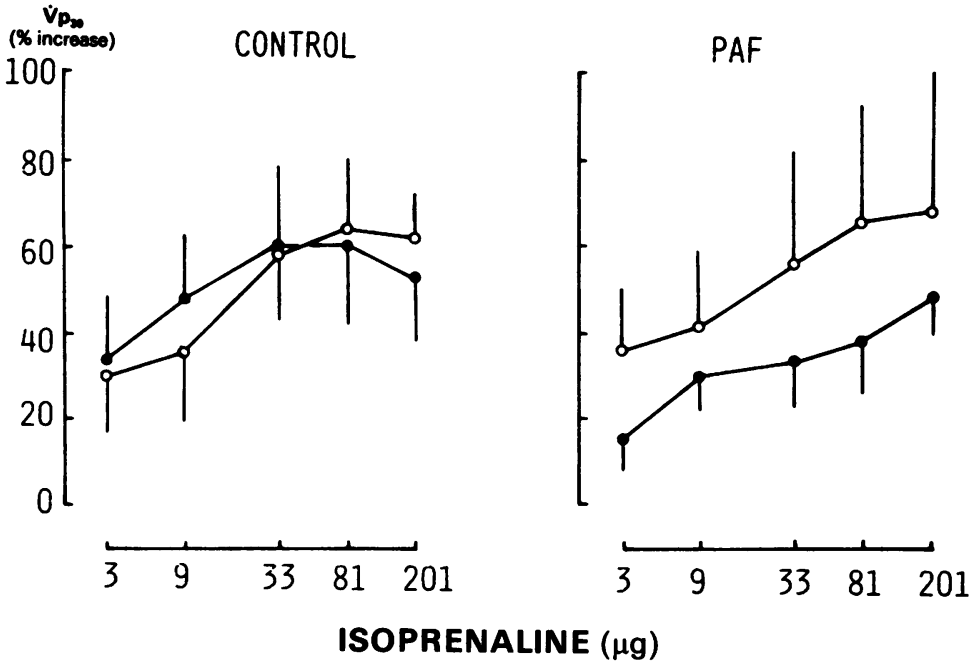

Fig 5 Mean (SEM) change in $V p_{30}$ in response to increasing doses of inhaled isoprenaline before (day 0, 0 ) and three days after (day 3, O) exposure to methacholine (control, left hand panel) and platelet activating factor $(P A F$, right hand panel). The decrease in responsiveness to isoprenaline observed after exposure to platelet activating factor was not significant.

ISOPRENALINE $(\mu \mathrm{g})$

interesting comparison with those from normal subjects. In a previous study of normal subjects ${ }^{18}$ we used a similar protocol except that the first dose of inhaled platelet activating factor was twice that administered to the asthmatic subjects in this study. The acute changes in airway calibre and airway responsiveness in the two groups on day 3 after platelet activating factor inhalation are compared in figure 6 . The falls in $\dot{V}_{30}$ were significantly larger in the normal subjects after inhalation of $24 \mu \mathrm{g}$ of platelet activating factor than in the asthmatic subjects after inhalation of $12 \mu \mathrm{g}$ (unpaired $t$ test: $\mathrm{p}<0.02$ ). Given the wide differences in methacholine responsiveness between the two groups, the asthmatic subjects being on average 25 times more responsive than normal subjects, these results suggest that individuals with asthma may not be more responsive to inhaled platelet activating factor than normal subjects. These observations are similar to those recently reported by Rubin and colleagues. ${ }^{5}$ We also did not find a significant relation between the acute airway response to platelet activating factor and methacholine responsiveness in asthmatic subjects (fig 2 ) as previously reported for normal subjects. ${ }^{4}$

The reasons why those with asthma are not more responsive to platelet activating factor than normal individuals are not clear. One possibility, if it is generated continuously in asthmatic but not normal airways, is that some degree of tachyphylaxis to the bronchoconstrictor effect of exogenously administered platelet activating factor is occurring. We have found a decreasing bronchoconstrictor response to

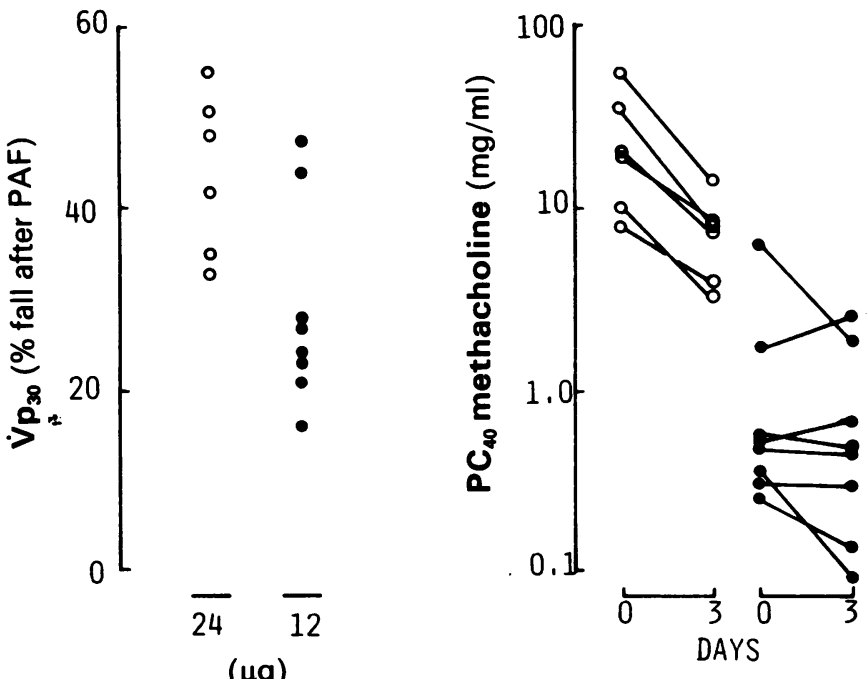

Fig 6 Comparison of the effect of inhalation of platelet activating factor $(P A F)$ in the eight asthmatic (O) subjects in this study and in six normal subjects (O) from a previous study using a similar protocol..$^{18}$ Left hand panel: Fall in $V p_{30}$, which was less in the asthmatic subjects after they had inhaled $12 \mu \mathrm{g}$ than in the normal subjects after they had inhaled 24 $\mu g(p<0.02)$. Right hand panel: Change in $P C_{10}$ on day 3 in six normal subjects ${ }^{8}$ (mean change threefold) and eight asthmatic subjects. 
successive inhalations when it is given every 15 minutes, but the duration of the tachyphylaxis is not known. This seems unlikely to be the entire reason, since the asthmatic airway does respond acutely to the initial doses, and with repeated inhalations, and shows tachyphylaxis similar to that of the normal subjects. Perhaps a more plausible explanation is the possibility that platelet activating factor induces airway narrowing by causing airway oedema in addition to airway smooth muscle contraction. It is very potent in causing airway microvascular leakage ${ }^{3}$ but has no direct effect on an isolated human airway smooth muscle preparation. ${ }^{22}$ The in vivo response to platelet activating factor may therefore be due partly to the development of airway oedema. This hypothesis is difficult to prove directly in man, but a response to airway oedema would account for the lack of correlation between the airway responsiveness to platelet activating factor and that to methacholine and for the absence of airway hyperresponsiveness to platelet activating factor in asthmatic subjects. As, however, cumulative dose-response relationships for platelet activating factor cannot be obtained because of the rapid development of tachyphylaxis, our observations must be interpreted with some caution.

There are also qualitative differences in the changes in methacholine responsiveness after platelet activating factor exposure between normal and asthmatic subjects. Rubin et al found no significant changes in airway responsiveness to methacholine in asthmatic subjects within one hour of exposure. ${ }^{5}$ We also found no significant decrease in $\mathrm{PC}_{40}$ in asthmatic subjects as a group, in contrast to the hyperresponsiveness induced by platelet activating factor in normal subjects. ${ }^{4518}$ Examination of individual responses within the asthmatic group suggests that there may be a subset (five of eight subjects) with a larger decrease in $\mathrm{PC}_{40}$ - more than 2.3 fold, which is outside the $95 \%$ confidence interval for the five "control" $\mathrm{PC}_{40}$ measurements in these subjects (fig 4). This change is similar in magnitude to the changes previously observed in normal subjects. ${ }^{4518}$ Overall, however, platelet activating factor seems to be less effective in inducing bronchial hyperresponsiveness in asthmatic than normal subjects. If it is released endogenously in the airways of those with asthma, any inflammatory mechanisms underlying bronchial hyperresponsiveness may be less readily effective because of tachyphylaxis. In addition, it may be more difficult to enhance the inflammatory processes that may underlie the maintenance of bronchial hyperresponsiveness and may already be present in the airways of those with mild asthma. ${ }^{23}$

We observed acute, transient falls in the circulating white cells, mainly due to a fall in the neutrophil count. This effect has been reported in animals, ${ }^{16}{ }^{17}$ and similar falls were observed after platelet activating factor inhalation in normal subjects. ${ }^{18} 21$ In these studies a fall in circulating platelet counts was also observed, but the doses administered (particularly in the human study) were much higher than those given in the present study. The mechanism(s) underlying the transient neutropenia remain to be determined. As the pulmonary vascular bed is a site of sequestration for some $10-20 \%$ of circulating neutrophils, ${ }^{24}$ platelet activating factor may be enhancing this effect by inducing pulmonary vasoconstriction. ${ }^{25}$ Whether the neutrophil is concerned in the mediation of the airway responses to platelet activating factor in man has not been determined.

In conclusion, we found that individuals with asthma seem to respond with a degree of bronchoconstriction similar to that of normal people. There were, however, no significant changes in bronchial responsiveness to methacholine or isoprenaline after platelet activating factor inhalation in the asthmatic subjects.

We thank Astrid Greenberry for her expert assistance in the preparation of this manuscript, and Geoff Nichol and Andrew Nunn for statistical help and advice. The work was supported by the Asthma Research Council and the Medical Research Council.

\section{References}

1 Barnes PJ, Chung KF, Page CP. Platelet-activating factor as a mediator of allergic disease. $J$ Allergy Clin Immunol 1988;81:919-34.

2 Barnes PJ, Chung KF. PAF closely mimics pathology of asthma. Trends Pharmacol Sci 1987;8:285-7.

3 Evans TW, Chung KF, Rogers DF, Barnes PJ. Effect of platelet-activating factor on airway vascular permeability: possible mechanisms. J Appl Physiol 1987;63:479-84.

4 Cuss FM, Dixon CMS, Barnes PJ. Effects of inhaled platelet activating factor on pulmonary function and $\mathrm{O}$ bronchial responsiveness in man. Lancet 1986;ii: $)$ 189-92.

5 Rubin AE, Smith LJ, Patterson R. The bronchoconstrictor properties of platelet-activating factor in $\%$ humans. Am Rev Respir Dis 1987;136:1145-51.

6 Robertson DN, Page CP. Effect of platelet agonists on airway reactivity and intrathoracic platelet accumula- $C$ tion. Br J Pharmacol 1987;92:105-11.

7 Chung KF, Aizawa H, Leikauf GD, Ueki IF, Evans TW, Nadel JA. Airway hyperresponsiveness induced by $\mathbb{\mathbb { D }}$ platelet-activating factor: role of thromboxane genera- $\stackrel{\oplus}{+}$ tion. J Pharmacol Exp Ther 1986;236:580-4.

8 Christman BW, Lefferts PL, Snapper JR. Effect of platelet activating factor on aerosol histamine respon- $\mathbb{D}$ ses in awake sheep. Am Rev Respir Dis 1987;135: $1267-70$. 
9 Wardlaw AJ, Moqbel R, Cromwell O, Kay AB. Plateletactivating factor. A potent chemotactic and chemokinetic factor for human eosinophils. $J$ Clin Invest 1986;78:1701-6.

10 Henocq E, Vargaftig BB. Accumulation of eosinophils in response to intracutaneous PAF-acether and allergens in man. Lancet 1986;i:1378-9.

11 Dunnill MS. The pathology of asthma with special reference to changes in the bronchial mucosa. J Clin Pathol 1960;13:27-33.

12 Frigas E, Gleich GJ. The eosinophil and the pathology of asthma. J Allergy Clin Immunol 1986;77:527-37.

13 Maridonneau-Parini I, Lagente V, Lefort J, Randon J, Russo-Marie F, Vargaftig BB. Desensitization of PAFinduced bronchoconstriction and to activation of alveolar macrophages by repeated inhalation of PAF in the guinea-pig. Biochem Biophys Res Commun 1985;131:42-9.

14 Barnes PJ, Grandordy BM, Page CP, Rhoden KJ, Robertson DN. The effect of platelet activating factor on pulmonary beta-adrenoceptors. $\mathrm{Br} J$ Pharmacol 1987;90:709-15.

15 Agrawal DK, Townley RG. Effect of platelet activating factor on beta-adrenoceptors in human lung. Biochem Biophys Res Commun 1987;143:1-6.

16 Desquand S, Touvay C, Randon J, et al. Interference of BN 52021 (ginkgolide B) with the bronchopulmonary effects of PAF-acether in the guinea pig. Eur $J$ Pharmacol 1986;127:83-95.

17 Halonen M, Palmer JD, Lohman IC, McManus LM,
Pinckard RN. Respiratory and circulatory alterations induced by acetyl glyceryl ether phosphorylcholine, a mediator of IgE anaphylaxis in the rabbit. Am Rev Respir Dis 1980;122:915-24.

18 Chung KF, Dent G, Barnes PJ. Effects of salbutamol on bronchoconstriction, bronchial hyperresponsiveness, and leucocyte responses induced by platelet activating factor in man. Thorax 1989;44:102-7.

19 Barnes PJ, Gribbin HR, Osmanliev D, Pride NB. Partial flow-volume curves to measure bronchodilator doseresponse curves in normal man. $J$ Appl Physiol 1981;50:1193-7.

20 Cohen L, Halliday M. Statistics for social scientists. London: Harper Raw, 1982:298-316.

21 Chung KF, Minette P, McCusker M, Barnes PJ. Ketotifen inhibits the cutaneous but not the airway responses to platelet-activating factor in man. $J$ Allergy Clin Immunol 1988;81:1192-7.

22 Schellenberg RR. Airway responses to platelet-activating factor. Am Rev Respir Dis 1987;136:528-31.

23 Laitinen LA, Heino M, Laitinen A, Kava T, Haahtela T. Damage of the airway epithelium and bronchial reactivity in patients with asthma. Am Rev Respir Dis 1985;131:599-606.

24 Cohen AB, Rossi M. Neutrophils in normal lungs. Am Rev Respir Dis 1983;127:S3-9.

25 Heffner JE, Shoemaker SA, Canham EM, et al. Acetyl glyceryl ether phosphorylcholine-stimulated human platelets cause pulmonary hypertension and edema in isolated rabbit lungs. J Clin Invest 1983;71:351-7. 